\title{
Lymphocyte Cell Kinase Activation Mediates Neuroprotection during Ischemic Preconditioning
}

\author{
Ok-Nam Bae, ${ }^{1,2}$ Krishnamurthy Rajanikant, ${ }^{1}$ Jiangyong Min, ${ }^{1}$ Jeremy Smith, ${ }^{1}$ Seung-Hoon Baek,,${ }^{1,3}$ Kelsey Serfozo, ${ }^{1}$ \\ Siamak Hejabian, ${ }^{1}$ Ki Yong Lee, ${ }^{1}$ Mounzer Kassab, ${ }^{1}$ and Arshad Majid ${ }^{1,4}$ \\ ${ }^{1}$ Division of Cerebrovascular Diseases and Department of Neurology and Ophthalmology, Michigan State University, East Lansing, Michigan 48824, \\ ${ }^{2}$ College of Pharmacy, Hanyang University, Ansan, Gyeonggido 426-791, Korea, ${ }^{3}$ College of Pharmacy, Ajou University, Suwon, Gyeonggido 443-749, Korea, \\ and ${ }^{4}$ Clinical Lead, Hyperacute Stroke Research Centre, Department of Neurology, Salford Royal Foundation Trust, Salford M6 8HD, England
}

The molecular mechanisms underlying preconditioning (PC), a powerful endogenous neuroprotective phenomenon, remain to be fully elucidated. Once identified, these endogenous mechanisms could be manipulated for therapeutic gain. We investigated whether lymphocyte cell kinase (Lck), a member of the Src kinases family, mediates PC. We used both in vitro primary cortical neurons and in vivo mouse cerebral focal ischemia models of preconditioning, cellular injury, and neuroprotection. Genetically engineered mice deficient in Lck, gene silencing using siRNA, and pharmacological approaches were used. Cortical neurons preconditioned with sublethal exposure to NMDA or oxygen glucose deprivation (OGD) exhibited enhanced Lck kinase activity, and were resistant to injury on subsequent exposure to lethal levels of NMDA or OGD. Lck gene silencing using siRNA abolished tolerance against both stimuli. $\mathrm{Lck}^{-1-}$ mice or neurons isolated from $\mathrm{Lck}^{-1-}$ mice did not exhibit PC-induced tolerance. An Lck antagonist administered to wild-type mice significantly attenuated the neuroprotective effect of PC in the mouse focal ischemia model. Using pharmacological and gene silencing strategies, we also showed that $\mathrm{PKC} \varepsilon$ is an upstream regulator of Lck, and Fyn is a downstream target of Lck. We have discovered that Lck plays an essential role in PC in both cellular and animal models of stroke. Our data also show that the PKC $\varepsilon$-Lck-Fyn axis is a key mediator of PC. These findings provide new opportunities for stroke therapy development.

\section{Introduction}

Ischemic tolerance induced by preconditioning $(\mathrm{PC})$ is an endogenous protective mechanism whereby short exposure to sublethal levels of a noxious stimulus results in protection from subsequent more severe levels of exposure to the stimulus (Zemke et al., 2004; Obrenovitch, 2008). PC occurs in a variety of organs including the heart and brain (Lo et al., 2003). Numerous preclinical in vitro and in vivo models of PC are available, and clinical data supporting preconditioning in human diseases also exist. For example, transient ischemic attacks (TIAs), caused by brief periods of interruption in blood flow to the brain, are associated with decreased stroke severity and improved outcome (Moncayo et al., 2000; Dirnagl et al., 2009). To date, all acute neuroprotective stroke therapies have failed in clinical trials, and, consequently, no neuroprotective therapies for acute stroke exist. An alternative strategy to reduce stroke severity may involve enhancing endogenous neuroprotection such as PC (Fisher and Ratan, 2003;

Received Dec. 12, 2011; revised Jan. 29, 2012; accepted Feb. 16, 2012.

Author contributions: 0.-N.B., K.R., J.M., J.S., and A.M. designed research; 0.-N.B., K.R., J.M., S.-H.B., K.S., and S.H. performed research; O.-N.B., K.R., J.M., S.-H.B., K.S., S.H., K.Y.L., M.K., and A.M. analyzed data; 0.-N.B. and A.M. wrote the paper.

This study was supported by an American Heart Association grant to A.M. and by a postdoctoral fellowship from the Korea Research Foundation (KRF-2007-357-E00036) to 0.-N.B.

The authors report no competing financial interests.

Correspondence should be addressed to Dr. Arshad Majid, Clinical Lead, Hyperacute Stroke Research Centre, Department of Neurology, Salford Royal Foundation Trust, Salford M68HD, England. E-mail: majidarshad@msn.com.

DOI:10.1523/JNEUROSCI.6273-11.2012

Copyright $\odot 2012$ the authors $\quad 0270-6474 / 12 / 327278-09 \$ 15.00 / 0$
Dirnagl et al., 2009). Although several mediators of PC have been proposed, such as hypoxia-inducible factor, heat shock proteins, erythropoietin, and ion channels (Kennedy and Buchan, 2005; Malhotra et al., 2006; Obrenovitch, 2008; Dirnagl et al., 2009), the exact mechanisms that mediate preconditioning are not yet fully understood.

Lymphocyte cell kinase (Lck), a member of the Src family kinases, has been shown to mediate diverse cellular pathways including cell survival, proliferation, differentiation, and cell death in many different cell types (Salmond et al., 2009). Previous studies using Lck knock-out mice demonstrated that Lck gene deletion abolished the cardioprotective effect of PC in myocardium (Ping et al., 1999, 2002). Although, Lck is expressed in the brain (Omri et al., 1996; Salter and Kalia, 2004), its role in neuroprotection and $\mathrm{PC}$ has not been previously investigated.

We investigated the role of Lck in PC in the brain using in vitro and in vivo ischemia models and show that Lck is a critical mediator of PC in brain. Furthermore, we show that Lck-associated $\mathrm{PC}$ is mediated through its interaction with $\mathrm{PKC} \varepsilon$ and activation of another Src kinase, Fyn. In this study, we provide new insights into the mechanisms underlying endogenous neuroprotection, and suggest a novel therapeutic candidate pathway for stroke prevention or treatment.

\section{Materials and Methods}

Materials. Cell culture media and reagents (Neurobasal A, B27, glutamine, and penicillin/streptomycin), Lipofectamine 2000, Dynabeads Protein G Immunoprecipitation kit, mouse anti-p59Fyn Ab, and rabbit 
anti-Src $\left[\mathrm{pY}^{418}\right] \mathrm{Ab}$ were obtained from Invitrogen. Poly-D-lysine, NMDA, 4',6-diamidino-2-phenylindole (DAPI), and propidium iodide (PI) were purchased from Sigma. Lactate dehydrogenase (LDH) assay kit (CytoTox 96 Non-Radioactive cytotoxicity assay) and ProFluor Srcfamily kinase assay kit were obtained from Promega. BCA Protein assay reagents, SuperSignal West Pico Chemiluminescent Substrate, RIPA cell lysis buffer, Halt protease and phosphatase inhibitor mixture, and OnTarget plus SMARTpool siRNA against mouse Lck, Fyn, or Yes and its nontargeting negative control siRNA were purchased from Thermo Fisher Scientific. RNeasy Mini kit was obtained from Qiagen, and BioPORTER reagent was from Genlantis. Mouse anti-protein kinase $\mathrm{C} \varepsilon$ $(\mathrm{PKC} \varepsilon) \mathrm{Ab}$ and mouse anti-p56Lck Ab were from BD Biosciences. Mouse anti- $\beta$-actin $A b$, rabbit anti-Yes $A b$, and mouse anti-glyderaldehyde-3phosphate dehydrogenase (GAPDH) Ab were purchased from Abcam, Cell Signaling Technology, and Millipore, respectively. All other reagents were used with highest purity available.

Primary cortical neuronal cultures. All animal procedures were approved by the Institutional Animal Care and Use Committee (IACUC) at Michigan State University. Primary cortical neuronal cultures were established as previously described (Yim et al., 2010). Briefly, cerebral cortices were isolated from C57BL/6 newborn mice at postnatal day 0 and dissociated in dissection media ( $81.8 \mathrm{mM} \mathrm{Na}_{2} \mathrm{SO}_{4}, 30 \mathrm{~mm} \mathrm{~K}_{2} \mathrm{SO}_{4}, 5.8 \mathrm{~mm}$ $\mathrm{MgCl}_{2}, 0.252 \mathrm{~mm} \mathrm{CaCl}_{2}, 1.5 \mathrm{~mm}$ HEPES, $20 \mathrm{~mm}$ glucose, and $0.001 \%$ phenol red, pH 7.6) supplemented with $4 \mathrm{~mm} \mathrm{~L}$-cysteine, $10 \mathrm{U} / \mathrm{ml}$ papain (Worthington), and $1000 \mathrm{U} / \mathrm{ml} \mathrm{DNase} \mathrm{(Roche)} \mathrm{for} 30 \mathrm{~min}$ at $37^{\circ} \mathrm{C}$. After dissociation, cells were washed with Neurobasal A and then triturated with pipette. Cells $\left(1 \times 10^{6}\right)$ were plated onto poly-D-lysine-precoated 12 well plates. Three days after plating, $50 \%$ of the medium was changed, and subsequently replaced every $3 \mathrm{~d}$. Neuronal cultures were maintained in $\mathrm{CO}_{2}$ incubator $\left(5 \% \mathrm{CO}_{2} / 95 \%\right.$ air balance) at $37^{\circ} \mathrm{C}$, and used between days in vitro (DIV) 7 and 11 .

Determination of NMDA-induced cytotoxicity. Delayed NMDAinduced cytotoxicity was measured at $24 \mathrm{~h}$ after NMDA exposure using PI-staining or LDH assay as previously described (Tauskela et al., 2003; Wetzel et al., 2008). On DIV 9, cultured neurons were exposed to NMDA for $20 \mathrm{~min}$ and maintained in $\mathrm{CO}_{2}$ incubator for $24 \mathrm{~h}$. Cells were stained with $5 \mu \mathrm{g} / \mathrm{ml}$ PI at $37^{\circ} \mathrm{C}$ for $30 \mathrm{~min}$, and examined by fluorescent microscopy (Nikon) or fluorescent microplate reader (Ascent, Thermo Lab Systems). The extent of LDH leakage was measured in conditioned media using a Cytotox 96 Non-Radioactive cytotoxicity assay. The cell viability in sister cells treated with $100 \mu \mathrm{M}$ NMDA was used as the total cell death $(100 \%)$.

In experiments with NMDA-induced PC, cells were exposed to sublethal dose of NMDA $(10 \mu \mathrm{M})$ for $20 \mathrm{~min}$ on DIV 8, and subsequently exposed to lethal dose of NMDA ( $50 \mu \mathrm{M})$ at $24 \mathrm{~h}$ after PC on DIV 9. Cell viability was measured as described above on DIV 10.

PKC $\varepsilon$ activity modulating peptides. The peptide inhibitor for PKC $\varepsilon$ translocation (EAVSLKPT; V1-2) (Chen et al., 2005) and PKC $\varepsilon$ selective agonist (HDAPIGYD; $\psi \varepsilon$ RACK) (Inagaki et al., 2005) were synthesized by Macromolecular Structure Facility (Department of Biochemistry, Michigan State University). $\varepsilon$ V1-2 or $\psi \varepsilon$ RACK was diluted and mixed with BioPORTER reagent (Alano et al., 2010). Cells were incubated with BioPORTER-peptide complex for $4 \mathrm{~h}$ at $37^{\circ} \mathrm{C}$. After transfection, cell were washed with complete culture media and immediately exposed to NMDA. Cell transfection efficiency was confirmed using parallel transfections with fluorescein-labeled control IgG, as suggested by the manufacturer.

Gene silencing with siRNAs. Primary cortical neurons were transfected with $10 \mathrm{~nm}$ siRNAs using Lipofectamine 2000 transfection reagent (Ueda et al., 2007). On DIV 5, neurons were incubated with Neurobasal A containing Lipofectamine $2000(0.2 \%)$ and $10 \mathrm{~nm}$ siRNAs against mouse Lck, Yes, or Fyn, or nontargeting negative control for $4 \mathrm{~h}$ at $37^{\circ} \mathrm{C}$. After transfection, the original medium collected before transfection was replaced. To ensure gene silencing efficiency, target mRNA or protein samples were collected after 48 and $96 \mathrm{~h}$ after siRNA transfection, and measured by quantitative real time PCR or Western blot, respectively.

Immunoprecipitation. Neuronal lysates were applied to immunoprecipitation using magnetic beads (Dynabeads, Invitrogen) (Gudz et al., 2006). Cell lysates were harvested using RIPA buffer, and centrifuged at $14,000 \times g$ for $15 \mathrm{~min}$. Protein concentrations were determined by BCA assay, and then adjusted to $1 \mathrm{mg} / \mathrm{ml}$. Five hundred microliters of lysates were applied to immunoprecipitation using specific anti-Lck or Fyn Abconjugated magnetic beads (Dynabeads, Invitrogen). Eluted immunoprecipitates were used for kinase assay or Western blot.

Lck/Fyn kinase activity. After immunoprecipitation with anti-Lck or Fyn Ab, eluted immunoprecipitates were analyzed using a ProFluor SrcFamily Kinase Assay (Watanabe et al., 2010). The total kinase amounts in immunoprecipitates were examined by Western blot, and the kinase activity from the corresponding control was defined as one-fold.

Western blot. After the cell lysate was collected using RIPA buffer supplemented with Halt protease/phosphatase inhibitor mixture, the protein concentrations were determined using BCA assay. The protein samples $(20 \mu \mathrm{g} / \mathrm{lane})$ were separated in $12 \%$ Tris-HCl SDSpolyacrylamide Ready Gels (Bio-Rad) and were transferred to PVDF membrane (Millipore). After blocking with 5\% BSA, membranes were incubated overnight at $4^{\circ} \mathrm{C}$ with primary antibodies of anti-Lck $(1: 1000)$, anti-Fyn (1:500), anti-p-Src/Fyn (1:1000), anti-PKC $\varepsilon$ (1:1000), anti-Yes (1:1000), anti-GAPDH (1:5000), or anti- $\beta$-actin (1:5000). Horseradish peroxidase-conjugated secondary antibodies (1:5000, Cell Signaling Technology) were used as secondary antibodies. The immune complexes were visualized by enhanced chemiluminescence using SuperSignal West Pico Chemiluminescent Substrate. Bands were quantified by NIH ImageJ program, and normalized by the corresponding loading controls of $\beta$-actin or GAPDH. All immunoblots were repeated for at least three independent experiments.

Quantitative real time PCR. Total RNA was extracted using RNeasy mini kit (Qiagen), and converted into cDNA using TaqMan reverse transcription kit (Applied Biosystems) for quantitative real-time PCR (qRTPCR). The specific primer sequences were as follows: $18 \mathrm{~S}$, forward: ACC GCA GCT AGG AAT AAT GGA; reverse: GCC TCA GTT CCG AAA ACC A; Lck, forward: TGG AGA ACA TTG ACG TGT GTG; reverse: ATC CCT CAT AGG TGA CCA GTG; and Fyn, forward: ACC TCC ATC CCG AAC TAC AAC; reverse: CGC CAC AAA CAG TGT CAC TC. Quantification of gene copies was performed on the 7500 Real-Time PCR system, using SYBR Green master mix (Applied Biosystems). PCR cycles consisted of three stages with an initial step at $95^{\circ} \mathrm{C}$ for $10 \mathrm{~min}$ followed by 40 cycles at $95^{\circ} \mathrm{C}$ for $15 \mathrm{~s}$ and $60^{\circ} \mathrm{C}$ for $1 \mathrm{~min}$, and a final stage for dissociation curve. Relative mRNA expressions were calculated by the comparative $\mathrm{C}_{\mathrm{T}}$ method $\left(2^{-\Delta \Delta \mathrm{Ct}}\right)$, and normalized to the endogenous 18 S control.

Oxygen glucose deprivation. Oxygen glucose deprivation (OGD) on primary cortical neurons was performed as previously described (Plesnila et al., 2001; Wetzel et al., 2008). On DIV 9, cells were washed, and the medium was replaced by glucose free Earl's balanced salt solution (5.4 mм KCl, $26.2 \mathrm{~mm} \mathrm{NaHCO}, 116 \mathrm{~mm} \mathrm{NaCl}, 1 \mathrm{~mm} \mathrm{NaH} \mathrm{NO}_{4}, 0.8 \mathrm{~mm}$ $\mathrm{MgSO}_{4}, 1.8 \mathrm{~mm} \mathrm{CaCl}_{2}$, and $0.01 \mathrm{~mm}$ glycine, $\mathrm{pH}$ 7.4). Cell plates were placed in a closed chamber (Billups-Rothenberg) filled with $5 \% \mathrm{CO}_{2} /$ $95 \% \mathrm{~N}_{2}$ for $2 \mathrm{~h}$ at $37^{\circ} \mathrm{C}$. OGD was terminated by returning the cultures to normal condition of complete Neurobasal A media and $5 \% \mathrm{CO}_{2} / 95 \%$ air. After $24 \mathrm{~h}$, OGD-induced cell death was examined by PI staining and LDH assay as described above. To induce OGD-PC, cells were exposed to sublethal OGD for $30 \mathrm{~min}$ on DIV 8, and lysed for Western blot/kinase assay or further exposed to lethal OGD for $2 \mathrm{~h}$ on DIV 9 for cytotoxicity assay.

Permanent middle cerebral artery occlusion. All animal procedures were approved by the Institutional Animal Care and Use Committee (IACUC) of the Michigan State University. Focal ischemia was induced by permanent middle cerebral artery occlusion (pMCAO) in male C57BL/6 mice (22-27 g; Charles River Laboratory) as previously described (Rajanikant et al., 2007). Mice were kept under isoflurane anesthesia during the entire procedure and their body temperature was maintained at $37^{\circ} \mathrm{C}$. A skinincision was made to create a small subtemporal craniotomy to expose the middle cerebral artery, and the artery was occluded using a bipolar coagulator. To ensure the completeness of the occlusion, the cerebral blood flow in the MCA territory was measured before and after MCAO by a laser doppler (Perimed PF-3). After incision closure, the animals were allowed to recover from the anesthesia. At $24 \mathrm{~h}$ after pMCAO, animals were killed, and then the brains were removed and sliced into 1 mm coronal sections, and stained with 2,3,5-triphenyl tetrazolium chlo- 



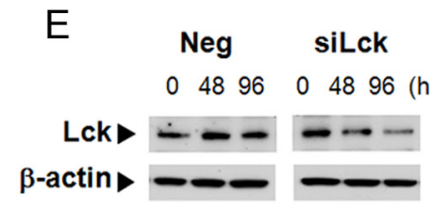

G
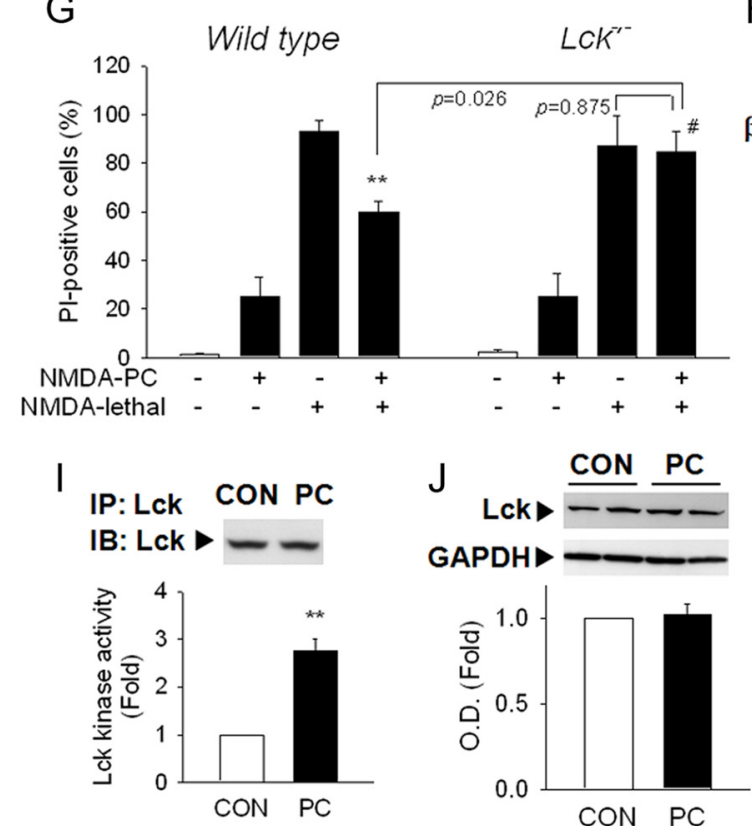
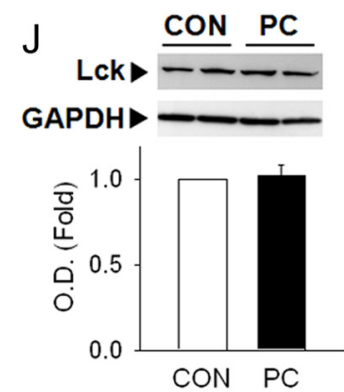

$\mathrm{F}$

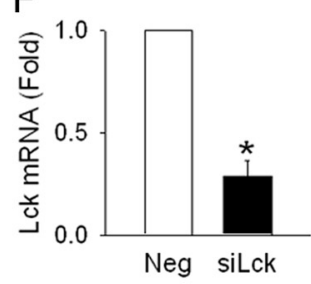

$\mathrm{H}$
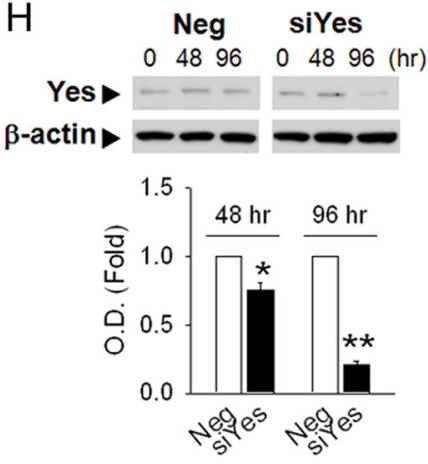

K

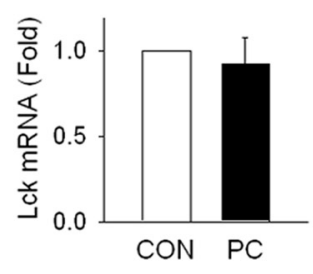

Figure 1. Lck mediates PC neuroprotection against NMDA-induced cytotoxicity in primary cortical neurons. $A, P C$ with NMDA (10 $\mu \mathrm{m})$ decreased vulnerability to lethal levels of NMDA (50 $\mu \mathrm{M})$. Neurons were stained with PI at $24 \mathrm{~h}$ after lethal NMDA exposure. Scale bar, $200 \mu \mathrm{m}$. $\boldsymbol{B}$, Lactate dehydrogenase (LDH) released into the medium was measured. $\boldsymbol{C}, \boldsymbol{D}$, Transfection of siRNA against Lck but not Yes reversed PC neuroprotection in PI-staining $(\boldsymbol{C})$ or LDH leakage $(\boldsymbol{D})$ at $24 \mathrm{~h}$ after lethal NMDA exposure. Neg, Nontargeting negative siRNA; siYes, siRNA against Yes. ${ }^{*} p<0.05$ versus NMDA lethal; ${ }^{*} p<0.05$ versus Neg +NMDAPC+NMDA lethal. $\boldsymbol{E}$, Lck protein levels were significantly decreased after silck transfection. $\beta$-actin, Loading control. $\boldsymbol{F}$, Lck mRNA was reduced at $48 \mathrm{~h}$ after silck transfection. ${ }^{*} p<0.05,{ }^{* *} p<$ 0.01 versus Neg. G, NMDA PC neuroprotection was not observed in cortical neurons from Lck ${ }^{-1-}$ mice. ${ }^{* *} p<0.01$ versus NMDA lethal; ${ }^{*} p<0.05$ versus wild-type NMDA PC + NMDA lethal. $\boldsymbol{H}$, siYes transfection decreased Yes protein level. $I$, Lck kinase activity was significantly increased after NMDA PC. Cell lysates were immunoprecipitated with $L c k$ Ab and applied to kinase assay. Total level of Lck in each immunoprecipitates was determined by Western blot. ${ }^{*} p<0.05$ versus control without PC; ${ }^{*} p<0.05$ versus NMDA PC. J, NMDA PC did not change total Lck protein levels. GAPDH, A loading control. $\boldsymbol{K}$, Gene transcription levels of Lck were not affected by NMDAPC. $\boldsymbol{A}, n=6 ; \boldsymbol{B}, \boldsymbol{I}, n=4 ; \boldsymbol{C}-\boldsymbol{H}, \boldsymbol{K}, n=3 ; \boldsymbol{J}, n=4-5$. All values are means \pm SEM and analyzed by Student's $t$ test. 
A

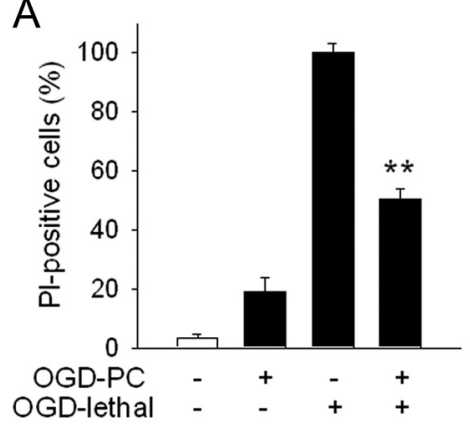

C

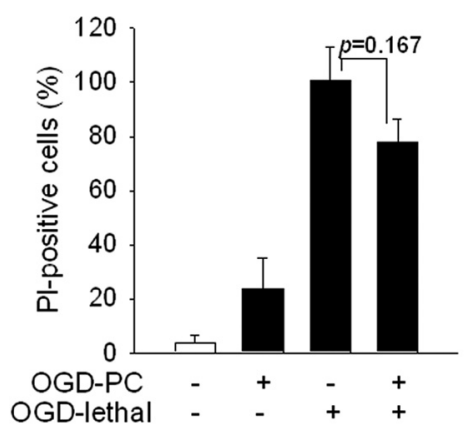

$\mathrm{B}$



$\mathrm{D}$
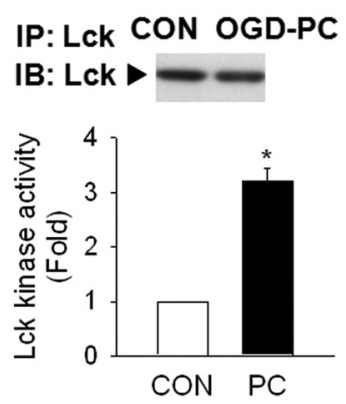

Figure 2. Lck is important in $0 G D P C$ neuroprotection. $A$, Primary cortical neurons were incubated in glucose free Earl's balanced salt solution under $5 \% \mathrm{CO}_{2} / 95 \% \mathrm{~N}_{2}$ at $37^{\circ} \mathrm{C}$ for $0 \mathrm{GD}$. OGD PC ( $30 \mathrm{~min}$ ) reduced lethal OGD ( $2 \mathrm{~h}$ )-induced neuronal cytotoxicity in PI-staining. OGD PC was performed $24 \mathrm{~h}$ before lethal OGD stimulation. Cytotoxicity was examined at $24 \mathrm{~h}$ after lethal $0 G D$ stimulation. $B$, Silencing Lck significantly reversed $0 G D P C$ neuroprotection. siRNAs were transfected $48 \mathrm{~h}$ before $O G D P C$, and OGD PC/lethal OGD exposure was performed as described above. ${ }^{*} p<0.05,{ }^{* *} p<0.01$ versus $0 G D$ lethal; ${ }^{\#} p<0.05$ versus Neg $+0 G D P C+0 G$ D lethal. C, Protective effect of OGD PC was not found in primary neurons from Lck $^{-1-}$ mice. $D$, Lck kinase activity was increased during OGD PC. Neuronal lysates were collected after OGD PC and used for Lck immunoprecipitation and kinase assay. Total level of $L c k$ in each immunoprecipitates was determined by Western blot. ${ }^{*} p<0.05$ versus control without PC. $\boldsymbol{A}, n=4 ; \boldsymbol{B}, \boldsymbol{D}, n=3 ; \boldsymbol{C}, n=5$. All values are means \pm SEM and analyzed by Student's $t$ test.

ride (TTC) solution (Ruscher et al., 2011). The infarct area was measured using the NIH ImageJ program from the scanned images of stained brain slices. The infarct volume in each slice was calculated by taking the average of the infarct areas on both sides of the slice and multiplying it by the section thickness.

In vivo preconditioning. PC was induced $48 \mathrm{~h}$ before pMCAO by exposing the animals for $2 \mathrm{~h}$ to a continuously flushed gas mixture of $8 \%$ oxygen $/ 92 \%$ nitrogen at a rate of $1.5 \mathrm{~L} / \mathrm{min}$. Control animals were exposed to ambient air. After $2 \mathrm{~h}$, the mice were returned to normal atmospheric conditions. At $48 \mathrm{~h}$ after PC, the mice were subjected to pMCAO and the differences in infarct volumes between the groups were determined at $24 \mathrm{~h}$ after pMCAO by TTC staining as described above. To determine the effect of A420983 on PC protection against brain infarction, mice were orally administered with vehicle or $18 \mathrm{mg} / \mathrm{kg}$ A420983 immediately after PC and every $12 \mathrm{~h}$ thereafter for $48 \mathrm{~h}$ before pMCAO.

Statistics. We calculated the means and SEM for all treatment groups. The data were subjected to Student's $t$ test to determine the significant differences between treatment groups. Statistical analysis was performed using SPSS software. In all cases, a $p$ value of $<0.05$ was considered significant.

\section{Results}

Lck mediates preconditioning in NMDA-induced neuronal death

Only cultures which were $>90 \%$ positive for neuronal specific markers were used. NMDA-induced delayed cytotoxicity in primary cortical neurons has been used as an in vitro model of ischemic neuronal cell death (Manzerra et al., 2001; Tauskela et al.,
2003; Lin et al., 2008). NMDA-induced $(10-100 \mu \mathrm{M})$ cytotoxicity was observed in a dose-dependent manner. Confirming previous reports, cells that were preconditioned by preexposure to sublethal NMDA $(10 \mu \mathrm{M})$ exhibited decreased vulnerability to subsequent exposure to lethal concentrations of NMDA $(50 \mu \mathrm{M})$ (Fig. 1A,B).

We then examined the effect of decreasing Lck protein on PC using siRNA against Lck and mutant mice deficient for the Lck gene. Lck gene silencing using siRNA abolished PC (Fig. 1C,D), suggesting that Lck plays a critical role in neuronal PC. Silencing efficiency was confirmed by demonstrating both decreased Lck protein and mRNA levels (Fig. 1E,F). Similarly, although cortical neurons isolated from $\mathrm{Lck}^{-/-}$mice exhibited a cytotoxic response to NMDA in a similar fashion to wild-type neurons, neurons from $\mathrm{Lck}^{-1-}$ mice could not be preconditioned (Fig. 1G). Significantly, silencing another Src kinase, Yes, by using siRNA against Yes did not affect PC (Fig. 1C, $D, H$ ), suggesting that not all Src family members mediate PC.

To determine whether changes in Lck kinase activity mediate PC, neuronal lysates were immunoprecipitated with Lck antibody. The total Lck amount in each immunoprecipitate was not different (Fig. $1 I$, top), but Lck kinase activity was significantly increased by NMDA PC (Fig. $1 I$ ). Neither the total Lck protein levels nor the mRNA levels were affected by NMDA PC (Fig. $1 J, K$ ), suggesting that enhanced Lck activity rather than enhanced enzyme levels mediate PC.

\section{Lck mediates PC in the OGD model of PC}

To confirm our findings in another in vitro model of PC, we used OGD, a well established in vitro model, for ischemic neuronal damage and PC (Stenzel-Poore et al., 2004; Wetzel et al., 2008). Neuronal cells were preconditioned with exposure to $30 \mathrm{~min}$ OGD. Confirming previous reports, preconditioned neurons exhibited decreased vulnerability to subsequent lethal exposure to $2 \mathrm{~h}$ OGD (Fig. 2A). Silencing Lck using siRNA abolished OGD PC protection (Fig. $2 B$ ), and similarly, neurons from Lck ${ }^{-1-}$ mice, mutant mice deficient for the Lck gene, could not be preconditioned by OGD (Fig. 2C). Lck kinase activation but not mRNA or protein levels (Fig. 2D) was increased after OGD PC in a similar pattern to NMDA PC. Together, these findings suggest that Lck mediates PC regardless of type of the preconditioning stimuli.

\section{Lck mediates PC in focal cerebral ischemia}

Next, we sought to determine the role of Lck in PC in vivo using the mouse pMCAO model. PC (exposure to $8 \%$ oxygen for $2 \mathrm{~h}$ ) of mice followed by pMCAO at $48 \mathrm{~h}$ after PC significantly reduced the infarct volume compared with the control group, as measured by TTC staining at $24 \mathrm{~h}$ after MCAO (Fig. $3 A$ ). To determine whether Lck influences in vivo PC neuro- 
protection, we used $\mathrm{Lck}^{-1-}$ mice and an orally active Lck antagonist, A420983 (Waegell et al., 2002). First, we examined whether the vulnerability to $\mathrm{pM}$ CAO is affected by Lck gene deletion (Fig. $3 B$ ) and found no significant difference in infarct volumes between wild-type, $\mathrm{Lck}^{+/-}$or $\mathrm{Lck}^{-/-}$mice (WT vs $\mathrm{Lck}^{+/-}, p=0.319$; WT vs $\mathrm{Lck}^{-/-}$, $p=0.229 ; \mathrm{Lck}^{+/-}$vs $\mathrm{Lck}^{-1-}, p=$ 0.961). Unlike wild-type mice that demonstrated decreased infarct volumes following PC, $\mathrm{Lck}^{-/-}$mice did not exhibit decreased vulnerability to focal ischemia after PC (Fig. 3C). Physiological parameters during surgical procedure were not different between the groups as shown in Table 1. Similarly, mice treated with A420983 did not exhibit decreased infarct volumes after PC compared with vehicle treated mice (Fig. 3D).

Protein kinase $\mathrm{C} \varepsilon$ regulates Lck activation in PC neuroprotection

Previous data suggest that Lck mediates cardioprotection through the formation of PKC $\varepsilon$-Lck signaling module (Ping et al., 1999, 2002). To investigate the upstream regulators of Lck in PC in the brain, we investigated the involvement of PKC $\varepsilon$ in the NMDA PC model. Pretreatment with a $\mathrm{PKC} \varepsilon$ inhibitor $(\varepsilon \mathrm{V} 1-2 ; 10$ $\mu \mathrm{M})$ abolished PC, suggesting that PC is mediated by $\mathrm{PKC} \varepsilon$ activation (Fig. $4 A, B$ ). Moreover, pharmacological activation of PKC $\varepsilon$ by $\psi \varepsilon$ RACK $(10 \mu \mathrm{M})$ simulated NMDA PC, resulting in decreased vulnerability to lethal NMDA toxicity in cortical neuronal cells (Fig. 4A, B).

Next, we sought to determine whether interaction between PKC $\varepsilon$ and Lck occurs in preconditioned neurons using coimmunoprecipitation (Ping et al., 2002). PKC $\varepsilon$ was found to coreside in Lckimmunoprecipitates, and this interaction was significantly increased after NMDA PC (Fig. 4C). After inhibiting PKC $\varepsilon$ by $\varepsilon V 1-2$, NMDA-induced Lck kinase activation during PC was abolished (Fig. 4D), suggesting that Lck activity is regulated by $\mathrm{PKC} \varepsilon$ activation during PC.

\section{Fyn is the downstream target of Lck}

Published data suggest that Lck can regulate Fyn, another member of the Src family kinases (Suzuki and Okumura-Noji, 1995; Filipp et al., 2008; Isosaka et al., 2008). To determine whether Fyn is the downstream target of Lck in PC, we first examined Fyn phosphorylation and activity in NMDA PC. Immunoblotting to Fyn phosphorylated at Tyr 417, a positive regulatory residue for its activation (Filipp et al., 2008), revealed that p-Fyn levels are significantly enhanced during NMDA PC (Fig. 5A). Similarly, Fyn kinase activity from Fyn-immunoprecipitates was increased by NMDA PC (Fig. 5B), suggesting that Fyn is activated during PC. While inhibition of Fyn by silencing Fyn (siFyn) transfection did not affect NMDA-induced cytotoxicity (Fig. 5C), si-


Figure 3. In vivo $\mathrm{PC}$ protection is abolished in $\mathrm{Lck}{ }^{-/-}$mice or by $\mathrm{Lck}$ antagonist. $\boldsymbol{A}$, In vivo $\mathrm{PC}$ was performed by exposing mice

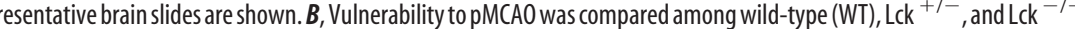
oberve significant difference was found. $C$, Protective effect of in vivo hypoxic PC against ischemic brain damage was not $20983(18 \mathrm{mg} / \mathrm{kg}$ ) was orally administered to mice immediately after $P($ and every $12 \mathrm{~h}$ thereafter for $48 \mathrm{~h}$ before focal ischemia. Anta, Lck antagonist A420983. ${ }^{* *} p<0.01$ versus control without $P C ;{ }^{*} p<0.05$ versus $P C . A, n=10-11 ; \boldsymbol{B}, n=11-15 ; \boldsymbol{C}, n=$ $8-9 ; \boldsymbol{D}, n=14-16$. All values are means \pm SEM and analyzed by Student's $t$ test.

Table 1. Physiological parameters during pMCAO

\begin{tabular}{|c|c|c|c|c|}
\hline & \multicolumn{2}{|l|}{ Wild type } & \multicolumn{2}{|l|}{$\mathrm{Lck}^{-1-}$} \\
\hline & Control & Preconditioned & Control & Preconditioned \\
\hline Body & 24.0 & .25 & $24.6 \pm 0.99$ & 1.25 \\
\hline Body temperature $\left({ }^{\circ} \mathrm{C}\right)$ & 37.4 & 37.3 & $37.3 \pm 0.07$ & 0.03 \\
\hline CBF before pMCAO & $333.0 \pm 18.3$ & $306.4 \pm 2.03$ & $311.1 \pm 12.0$ & $315.0 \pm 13.5$ \\
\hline CBF after pMCAO & $58.0 \pm 4.90$ & $49.5 \pm 1.96$ & $50.0 \pm 5.00$ & $52.5 \pm 4.53$ \\
\hline Reduction of CBF (\%) & $82.8 \pm 0.66$ & $83.8 \pm 0.60$ & $84.1 \pm 1.10$ & $83.4 \pm 0.91$ \\
\hline
\end{tabular}

Values are means $\pm \mathrm{SEM}$. CBF, Cerebral blood flow.

Fyn significantly abolished PC (Fig. 5D), reflecting that Fyn activation is critical for PC. Silencing efficiency was determined (Fig. 5E). We also investigated the role of Fyn in PC using OGD ischemia model, and found similar effects to NMDA PC (Fig. $5 F, G$ ).

Next we examined changes in p-Fyn levels after silencing Lck using siRNA or in neurons from $\mathrm{Lck}^{-/-}$mice. NMDA PCinduced Fyn phosphorylation was not increased after Lck gene silencing with siRNA or in neurons from $\mathrm{Lck}^{-1-}$ mice (Fig. $5 H, I)$, implying that Lck is the upstream regulator of Fyn activation. While Fyn is regulated by Lck, siFyn did not affect PC- 



Future studies will also need to explore the relative contribution of Lck and Fyn at various time intervals after PC, because rapid tolerance and delayed tolerance may be mechanistically distinct (Bright et al., 2008; Obrenovitch, 2008).

\section{The role of $\mathrm{PKC} \varepsilon$ in $\mathrm{PC}$}

Previous studies showed that $\mathrm{PKC} \varepsilon$ is an important mediator of PC in both heart and brain (Raval et al., 2003; Chou and Messing, 2005; Jia et al., 2007; Bright et al., 2008; DeFazio et al., 2009). PKC $\varepsilon$ is activated by a number of preconditioning stimuli, including hypoxia and transient ischemia. Downstream targets of $\mathrm{PKC} \varepsilon$ are many and include GABA signaling, mitochondrial function alteration, and extracellular signal-regulated kinases (ERKs) (Jia et al., 2007; Dave et al., 2008; DeFazio et al., 2009). However, the precise molecular targets of $\mathrm{PKC} \varepsilon$ still remain unclear. It is unlikely that PC involves a single obligatory mediator, and it is likely that there is activation of a constellation of different pathways that ultimately leads to tolerance (Brooks and Hearse, 1996). It is possible that other mediators and pathways may play a greater role depending on the PC stimulus. Studying other PC models will be important to better understand this complicated endogenous

induced Lck kinase activation (Fig. 5J), confirming that Fyn is the downstream target of Lck. Notably, $\varepsilon$ V1-2 reversed PC-induced Fyn phosphorylation (Fig. $5 K$ ), suggesting that the PKC $\varepsilon$-LckFyn axis is critical in PC.

\section{Discussion}

Our data provide new insights into the role of Lck in PC in the brain. Using in vitro models of PC, we showed that enhanced Lck kinase activity mediates PC. Neurons derived from $\mathrm{Lck}^{-1-}$ mice or neurons in which the Lck gene was silenced by siRNA could not be preconditioned. We also showed that PKC $\varepsilon$, a kinase that has been shown to be an important mediator of PC, is an upstream activator of Lck. Significantly, we have identified Fyn as a downstream target for Lck. Lck activation during PC leads to the activation of Fyn and silencing Fyn abolished PC. The important role of Lck was verified in vivo using an animal model of stroke. Lck gene deletion or pharmacological Lck antagonism blocked $\mathrm{PC}$ in vivo. Together, our data show that the PKC $\varepsilon$-Lck-Fyn signaling axis is an important mediator of PC. We cannot, however, exclude the possibility that Lck and/or Fyn could be activated by other yet-to be-identified upstream signals.

We used sublethal NMDA, OGD, and hypoxia to induce tolerance, but other models also exist (McLaughlin et al., 2003; Hoyte et al., 2006; Dave et al., 2008; Hu et al., 2010). Whether Lck plays a role in those preconditioning paradigms is not known. Although we used highly purified neuronal cultures, the potential influence of small amounts of other non-neuronal cells such as astrocytes and microglia cannot be entirely discounted and need further investigation. For the in vivo studies, we determined $24 \mathrm{~h}$ outcomes (infarct volume). Long-term outcomes (both histological and behavioral) remain to be determined in future studies. neuroprotective mechanism.

\section{Lck-a novel mediator of PC in brain}

Lck has been primarily investigated in the immune system in T lymphocytes. Lck plays an essential role in T cell receptor (TCR) signaling, modulating $\mathrm{T}$ cell activation and differentiation (Palacios and Weiss, 2004; Salmond et al., 2009). Recent data also suggest that Lck plays a role in mitochondrial signaling in apoptosis (Samraj et al., 2006; Kim et al., 2008). Until now, most studies have focused on the selective inhibition of Lck for therapeutic immunosuppression and treatment of immunological diseases, such as rheumatoid arthritis, based on its role in the immune system (Benati and Baldari, 2008; Meyn and Smithgall, 2008). Our data show that Lck activation contributes to PC and that inhibition of Lck abolishes PC. Whether activation of Lck would induce neuroprotection is not known and selective Lck activators are not available at this time. Although recent data suggest that Unc 119 can activate Lck in T cells (Gorska et al., 2004), it can also activate other Src kinases that would make it difficult to tease out the precise role of Lck activation. Another strategy worthy of further investigation may involve using PKC $\varepsilon$ activators to activate Lck.

Lck can also modulate the activity of other Src family kinase members such as Fyn, by phosphorylation of its active site Tyr 417 (Filipp et al., 2003). Previous studies suggest that Lck and Fyn have overlapping cellular functions and are closely related to each other (Filipp et al., 2003, 2008). However, this has not been previously examined in PC or in the brain. Our data show that neurons from $\mathrm{Lck}^{-1-}$ mice or wild-type neurons transfected with siRNA against Lck (siLck) exhibited significantly reduced Fyn 
A


G

IP: Fyn CON OGD-PC IB: p-Fyn



I

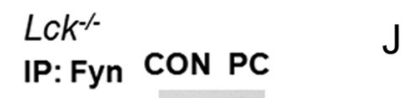

IB: p-Fyn $\triangleright-$

IB: Fyn $>-$

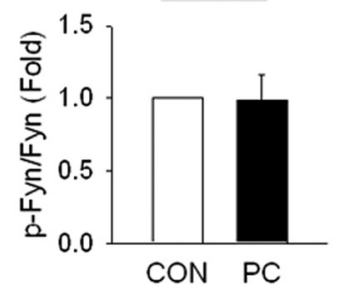

IP: Fyn CON PC

IB: Fyn $\triangleright-$



E Neg

04896

Fyn --

$\beta$-actin $>-$

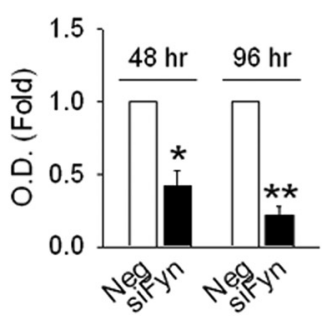

$\mathrm{H}$

IP: Fyn $\frac{\text { CON }}{\mathbf{N} \text { siL }} \frac{\text { PC }}{\mathbf{N} \text { siL }}$

IB: p-Fyn •

IB: Fyn •
C

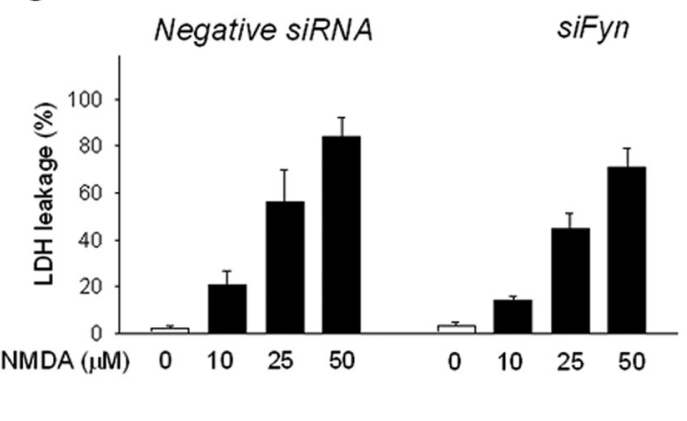

siFyn $\quad F$ 04896 (hr)

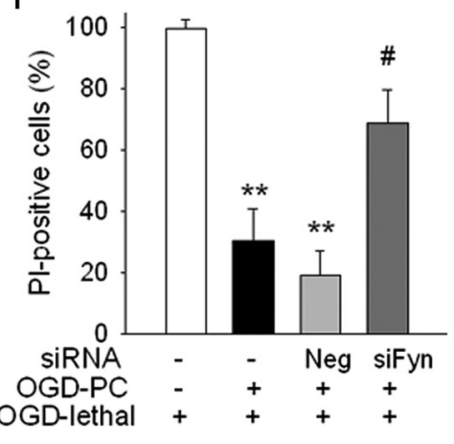

J
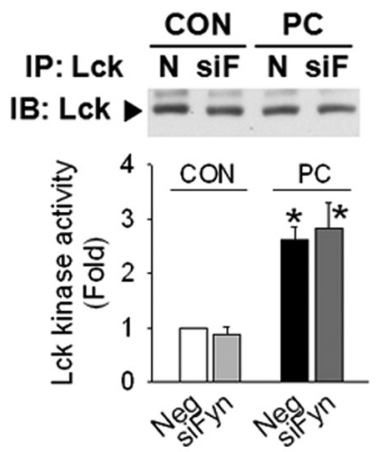

$\mathrm{K}$

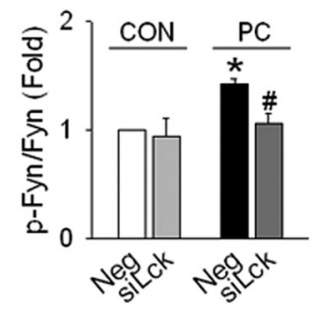
IP: Fyn $\frac{\text { CON }}{\operatorname{Veh} \varepsilon V} \frac{P C}{V e h \varepsilon V}$

IB: p-Fyn $>-\cdots-$

IB: Fyn $\triangleright$

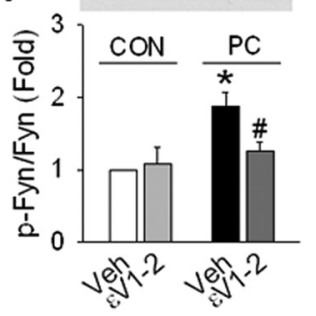

Figure 5. Fyn is activated by $L$ Lck during $P C$ neuroprotection. $A$, The active form of Fyn was increased after NMDA PC. Phosphorylation of Fyn at Tyr 417 was examined by Western blot after immunoprecipitation with Fyn Ab. Total levels of Fyn in each immunoprecipitate was also determined. $\boldsymbol{B}$, Fyn kinase activity was enhanced by NMDAPC. ${ }^{*} p<0.05$ versus control without PC. C, NMDA-induced cytotoxicity was examined after siFyn. D, Silencing Fyn reversed PC neuroprotection. siFyn was transfected $48 \mathrm{~h}$ before $\mathrm{PC}$, and $\mathrm{PC}$ was applied at $24 \mathrm{~h}$ before the lethal stimuli. Cytotoxicity was determined at $24 \mathrm{~h}$ after lethal NMDA exposure. ${ }^{*} p<0.05$ versus NMDA lethal; ${ }^{*} p<0.05$ versus Neg + NMDA PC+NMDA lethal. $\boldsymbol{E}$, Fyn levels were decreased by siFyn transfection. ${ }^{*} p<0.05$, ${ }^{* *} p<0.01$ versus Neg. $\boldsymbol{F}$, Silencing Fyn significantly reversed $0 \mathrm{GD} P$ P neuroprotection. siRNAs were transfected $48 \mathrm{~h}$ before $0 \mathrm{GDPC}$, and $0 \mathrm{GD} P$ PC/lethal $0 \mathrm{GD}$ exposure was performed as described above. ${ }^{* *} p<0.01$ versus $0 \mathrm{GD}$ lethal; ${ }^{\#} p<0.05$ versus Neg + OGD PC + OGD lethal. G, Active form of p-Fyn was enhanced by OGD PC in cortical neurons. ${ }^{*} p<0.05$ versus CON without OGD PC. $\boldsymbol{H}$, Fyn activation during PC was reversed by silencing Lck. silck was transfected $48 \mathrm{~h}$ before $\mathrm{PC}$. $\mathrm{p}$-Fyn or Fyn levels were examined by Western blot after Fyn-immunoprecipitation. N, Nontargeting negative siRNA; sil, silck. ${ }^{*} p<0.05$ versus Neg without PC; ${ }^{\#} p<0.05$ versus Neg with PC. $I$, Fyn activation by $\mathrm{PC}$ was not observed in neurons from $\mathrm{Lck}^{-1-}$ mice. J, Silencing Fyn did not influence Lck kinase activation during PC. Lck kinase activity was determined in Lckimmunoprecipitates after sifyn transfection and PC. siF, Silencing Fyn. ${ }^{*} p<0.05$ versus Neg without PC. $K$, Inhibition of PKC $\varepsilon$ decreased Fyn activation during PC. $\varepsilon V 1-2$ was treated by BioP0RTER before PC, and cell lysates were collected after $P C$ for Fyn immunoprecipitation and Western blot. $\varepsilon V, \varepsilon V 1-2$; Veh, vehicle control. ${ }^{*} p<0.05$ versus vehicle control without $P C$; ${ }^{\#} p<0.05$ versus Vehicle $+N M D A P C . A-C$, $\boldsymbol{E}, \mathbf{G}-\boldsymbol{K}, n=3 ; \mathbf{D}, \boldsymbol{F}, n=4$. All values are means \pm SEM and analyzed by Student's $t$ test. 
activation and phosphorylation induced by PC, suggesting that Lck modulates Fyn activation in neurons. While it appears that Lck is responsible for Fyn activation during PC, silencing Fyn did not affect PC-induced Lck activation, suggesting that Fyn activation is downstream of Lck.

\section{Downstream targets of Fyn}

The precise function of Fyn in the brain is not known. Fyn regulates NMDA receptors by the phosphorylation of its subunits (Salter and Kalia, 2004; Wu et al., 2007), which modulate NMDA receptor channel activity (Takasu et al., 2002). Following transient ischemia in rats, phosphorylation of the NR2A and, to a lesser extent, NR2B subunits of the NMDA receptor is increased (Takagi et al., 1999). The association between Fyn and NR2A following ischemia is accompanied by increased NR2A phosphorylation (Hou et al., 2003; Jiang et al., 2008). Ischemia also enhances the association between Fyn and other proteins in the NMDA receptor complex, such as PSD-95 and the L-type voltage gated calcium channel (Hou et al., 2003). Administration of a selective NR2A antagonist increased neuronal death and abolished preconditioning, whereas administration of an NR2B antagonist decreased neuronal death and enhanced the preconditioning effect (Chen et al., 2008). Fyn has been implicated in the phosphorylation and activation of both of these subunits, therefore it is possible that Fyn activity modulates preconditioning by influencing NR2A and NR2B activity. Another potential downstream candidate target is carveolin, a scaffolding protein that may also influence the activation of NMDA receptors (Head et al., 2008). Although our laser Doppler studies did not show any differences in blood flow between experimental groups in the in vivo studies, we cannot, however, discount the possibility that changes in blood flow may have occurred in the penumbra of the infarct. The precise downstream pathways that are modulated by Fyn activation are not known and need further investigation.

\section{Other Src family members}

Although the role of Src family kinases in neurons has been investigated in previous studies, the individual importance of each family member is not fully understood due to the lack of selective inhibitors/activators. Conventional inhibitors such as PP1 and PP2 lack selectivity (Hanke et al., 1996). To overcome this, we used RNA silencing to inhibit specific Src family members, Lck, Fyn, and Yes. We demonstrated that Lck and Fyn, but not Yes, are involved in PC. It is possible that other Src kinases may also be involved in PC and their function may not be mutually exclusive. An important point for consideration when manipulating Src kinases is that they may enhance angiogenesis that may facilitate recovery after stroke (Schlessinger, 2000; Slevin et al., 2006).

\section{Implications}

A desperate need exists for new stroke therapies (Fagan, 2010). Although PC is a powerful endogenous neuroprotective mechanism, translation of preclinical findings into therapies still remains a challenge (Keep et al., 2010). Our data suggest that selective activation of Lck or Fyn may represent a novel therapeutic strategy for stroke therapy development.

\section{References}

Alano CC, Garnier P, Ying W, Higashi Y, Kauppinen TM, Swanson RA (2010) NAD + depletion is necessary and sufficient for poly(ADPribose) polymerase-1-mediated neuronal death. J Neurosci 30:2967-2978.

Benati D, Baldari CT (2008) SRC family kinases as potential therapeutic targets for malignancies and immunological disorders. Curr Med Chem 15:1154-1165.

Bright R, Sun GH, Yenari MA, Steinberg GK, Mochly-Rosen D (2008) epsilonPKC confers acute tolerance to cerebral ischemic reperfusion injury. Neurosci Lett 441:120-124.

Brooks G, Hearse DJ (1996) Role of protein kinase C in ischemic preconditioning: player or spectator? Circ Res 79:627-630.

Chen M, Lu TJ, Chen XJ, Zhou Y, Chen Q, Feng XY, Xu L, Duan WH, Xiong ZQ (2008) Differential roles of NMDA receptor subtypes in ischemic neuronal cell death and ischemic tolerance. Stroke 39:3042-3048.

Chen Y, Cantrell AR, Messing RO, Scheuer T, Catterall WA (2005) Specific modulation of $\mathrm{Na}+$ channels in hippocampal neurons by protein kinase C epsilon. J Neurosci 25:507-513.

Chou WH, Messing RO (2005) Protein kinase C isozymes in stroke. [Review]. Trends Cardiovasc Med 15:47-51.

Dave KR, DeFazio RA, Raval AP, Torraco A, Saul I, Barrientos A, PerezPinzon MA (2008) Ischemic preconditioning targets the respiration of synaptic mitochondria via protein kinase C epsilon. J Neurosci 28:4172-4182.

DeFazio RA, Raval AP, Lin HW, Dave KR, Della-Morte D, Perez-Pinzon MA (2009) GABA synapses mediate neuroprotection after ischemic and epsilonPKC preconditioning in rat hippocampal slice cultures. J Cereb Blood Flow Metab 29:375-384.

Dirnagl U, Becker K, Meisel A (2009) Preconditioning and tolerance against cerebral ischemia: from experimental strategies to clinical use. Lancet Neurol 8:398-412.

Fagan SC (2010) Stroke: measuring disease-free life after thrombolysis. Nat Rev Neurol 6:361-362.

Filipp D, Zhang J, Leung BL, Shaw A, Levin SD, Veillette A, Julius M (2003) Regulation of Fyn through translocation of activated Lck into lipid rafts. J Exp Med 197:1221-1227.

Filipp D, Moemeni B, Ferzoco A, Kathirkamathamby K, Zhang J, Ballek O, Davidson D, Veillette A, Julius M (2008) Lck-dependent Fyn activation requires $\mathrm{C}$ terminus-dependent targeting of kinase-active Lck to lipid rafts. J Biol Chem 283:26409-26422.

Fisher M, Ratan R (2003) New perspectives on developing acute stroke therapy. Ann Neurol 53:10-20.

Gorska MM, Stafford SJ, Cen O, Sur S, Alam R (2004) Unc119, a novel activator of Lck/Fyn, is essential for $\mathrm{T}$ cell activation. J Exp Med 199:369-379.

Gudz TI, Komuro H, Macklin WB (2006) Glutamate stimulates oligodendrocyte progenitor migration mediated via an alphav integrin/myelin proteolipid protein complex. J Neurosci 26:2458-2466.

Hanke JH, Gardner JP, Dow RL, Changelian PS, Brissette WH, Weringer EJ, Pollok BA, Connelly PA (1996) Discovery of a novel, potent, and Src family-selective tyrosine kinase inhibitor. Study of Lck- and FynTdependent T cell activation. J Biol Chem 271:695-701.

Head BP, Patel HH, Tsutsumi YM, Hu Y, Mejia T, Mora RC, Insel PA, Roth DM, Drummond JC, Patel PM (2008) Caveolin-1 expression is essential for $\mathrm{N}$-methyl-D-aspartate receptor-mediated Src and extracellular signalregulated kinase $1 / 2$ activation and protection of primary neurons from ischemic cell death. FASEB J 22:828-840.

Hou XY, Zhang GY, Yan JZ, Liu Y (2003) Increased tyrosine phosphorylation of alpha(1C) subunits of L-type voltage-gated calcium channels and interactions among Src/Fyn, PSD-95 and alpha(1C) in rat hippocampus after transient brain ischemia. Brain Res 979:43-50.

Hoyte LC, Papadakis M, Barber PA, Buchan AM (2006) Improved regional cerebral blood flow is important for the protection seen in a mouse model of late phase ischemic preconditioning. Brain Res 1121:231-237.

Hu H, Yamashita S, Hua Y, Keep RF, Liu W, Xi G (2010) Thrombininduced neuronal protection: role of the mitogen activated protein kinase/ribosomal protein S6 kinase pathway. Brain Res 1361:93-101.

Inagaki K, Begley R, Ikeno F, Mochly-Rosen D (2005) Cardioprotection by epsilon-protein kinase $\mathrm{C}$ activation from ischemia: continuous delivery and antiarrhythmic effect of an epsilon-protein kinase C-activating peptide. Circulation 111:44-50.

Isosaka T, Hattori K, Kida S, Kohno T, Nakazawa T, Yamamoto T, Yagi T, Yuasa S (2008) Activation of Fyn tyrosine kinase in the mouse dorsal hippocampus is essential for contextual fear conditioning. Eur J Neurosci 28:973-981.

Jia J, Wang X, Li H, Han S, Zu P, Li J (2007) Activations of nPKCepsilon and ERK1/2 were involved in oxygen-glucose deprivation-induced neuropro- 
tection via NMDA receptors in hippocampal slices of mice. J Neurosurg Anesthesiol 19:18-24.

Jiang X, Mu D, Biran V, Faustino J, Chang S, Rincón CM, Sheldon RA, Ferriero DM (2008) Activated Src kinases interact with the $N$-methyl-Daspartate receptor after neonatal brain ischemia. Ann Neurol 63:632-641.

Keep RF, Wang MM, Xiang J, Hua Y, Xi G (2010) Is there a place for cerebral preconditioning in the clinic? Transl Stroke Res 1:4-18.

Kennedy J, Buchan AM (2005) C-EPO: ready for prime-time preconditioning? [Review]. Cerebrovasc Dis 19:272-273.

Kim MJ, Park MT, Yoon CH, Byun JY, Lee SJ (2008) Activation of Lck is critically required for sphingosine-induced conformational activation of Bak and mitochondrial cell death. Biochem Biophys Res Commun 370:353-358.

Lin CH, Chen PS, Gean PW (2008) Glutamate preconditioning prevents neuronal death induced by combined oxygen-glucose deprivation in cultured cortical neurons. Eur J Pharmacol 589:85-93.

Lo EH, Dalkara T, Moskowitz MA (2003) Mechanisms, challenges and opportunities in stroke. Nat Rev Neurosci 4:399-415.

Malhotra S, Savitz SI, Ocava L, Rosenbaum DM (2006) Ischemic preconditioning is mediated by erythropoietin through PI-3 kinase signaling in an animal model of transient ischemic attack. J Neurosci Res 83:19-27.

Manzerra P, Behrens MM, Canzoniero LM, Wang XQ, Heidinger V, Ichinose T, Yu SP, Choi DW (2001) Zinc induces a Src family kinase-mediated up-regulation of NMDA receptor activity and excitotoxicity. Proc Natl Acad Sci USA 98:11055-11061.

McLaughlin B, Hartnett KA, Erhardt JA, Legos JJ, White RF, Barone FC, Aizenman E (2003) Caspase 3 activation is essential for neuroprotection in preconditioning. Proc Natl Acad Sci USA 100:715-720.

Meyn MA 3rd, Smithgall TE (2008) Small molecule inhibitors of Lck: the search for specificity within a kinase family. Mini Rev Med Chem 8:628-637.

Moncayo J, de Freitas GR, Bogousslavsky J, Altieri M, van Melle G (2000) Do transient ischemic attacks have a neuroprotective effect? Neurology 54:2089-2094.

Obrenovitch TP (2008) Molecular physiology of preconditioning-induced brain tolerance to ischemia. Physiol Rev 88:211-247.

Omri B, Crisanti P, Marty MC, Alliot F, Fagard R, Molina T, Pessac B (1996) The Lck tyrosine kinase is expressed in brain neurons. J Neurochem 67:1360-1364.

Palacios EH, Weiss A (2004) Function of the Src-family kinases, Lck and Fyn, in T-cell development and activation. Oncogene 23:7990-8000.

Ping P, Zhang J, Zheng YT, Li RC, Dawn B, Tang XL, Takano H, Balafanova Z, Bolli R (1999) Demonstration of selective protein kinase C-dependent activation of Src and Lck tyrosine kinases during ischemic preconditioning in conscious rabbits. Circ Res 85:542-550.

Ping P, Song C, Zhang J, Guo Y, Cao X, Li RC, Wu W, Vondriska TM, Pass JM, Tang XL, Pierce WM, Bolli R (2002) Formation of protein kinase C (epsilon)-Lck signaling modules confers cardioprotection. J Clin Invest 109:499-507.

Plesnila N, Zinkel S, Le DA, Amin-Hanjani S, Wu Y, Qiu J, Chiarugi A, Thomas SS, Kohane DS, Korsmeyer SJ, Moskowitz MA (2001) BID mediates neuronal cell death after oxygen/ glucose deprivation and focal cerebral ischemia. Proc Natl Acad Sci USA 98:15318-15323.

Rajanikant GK, Zemke D, Senut MC, Frenkel MB, Chen AF, Gupta R, Majid A (2007) Carnosine is neuroprotective against permanent focal cerebral ischemia in mice. Stroke 38:3023-3031.

Raval AP, Dave KR, Mochly-Rosen D, Sick TJ, Pérez-Pinzón MA (2003) Epsilon PKC is required for the induction of tolerance by ischemic and NMDA-mediated preconditioning in the organotypic hippocampal slice. J Neurosci 23:384-391.
Ruscher K, Shamloo M, Rickhag M, Ladunga I, Soriano L, Gisselsson L, Toresson H, Ruslim-Litrus L, Oksenberg D, Urfer R, Johansson BB, Nikolich K, Wieloch T (2011) The sigma-1 receptor enhances brain plasticity and functional recovery after experimental stroke. Brain 134:732-746.

Salmond RJ, Filby A, Qureshi I, Caserta S, Zamoyska R (2009) T-cell receptor proximal signaling via the Src-family kinases, Lck and Fyn, influences T-cell activation, differentiation, and tolerance. Immunol Rev 228:9-22.

Salter MW, Kalia LV (2004) Src kinases: a hub for NMDA receptor regulation. Nat Rev Neurosci 5:317-328.

Samraj AK, Stroh C, Fischer U, Schulze-Osthoff K (2006) The tyrosine kinase Lck is a positive regulator of the mitochondrial apoptosis pathway by controlling Bak expression. Oncogene 25:186-197.

Schlessinger J (2000) New roles for Src kinases in control of cell survival and angiogenesis. Cell 100:293-296.

Slevin M, Kumar P, Gaffney J, Kumar S, Krupinski J (2006) Can angiogenesis be exploited to improve stroke outcome? Mechanisms and therapeutic potential. Clin Sci 111:171-183.

Stenzel-Poore MP, Stevens SL, Simon RP (2004) Genomics of preconditioning. Stroke 35:2683-2686.

Suzuki T, Okumura-Noji K (1995) NMDA receptor subunits epsilon 1 (NR2A) and epsilon 2 (NR2B) are substrates for Fyn in the postsynaptic density fraction isolated from the rat brain. Biochem Biophys Res Commun 216:582-588.

Takagi N, Cheung HH, Bissoon N, Teves L, Wallace MC, Gurd JW (1999) The effect of transient global ischemia on the interaction of Src and Fyn with the $N$-methyl-D-aspartate receptor and postsynaptic densities: possible involvement of Src homology 2 domains. J Cereb Blood Flow Metab 19:880-888.

Takasu MA, Dalva MB, Zigmond RE, Greenberg ME (2002) Modulation of NMDA receptor-dependent calcium influx and gene expression through EphB receptors. Science 295:491-495.

Tauskela JS, Brunette E, Monette R, Comas T, Morley P (2003) Preconditioning of cortical neurons by oxygen-glucose deprivation: tolerance induction through abbreviated neurotoxic signaling. Am J Physiol Cell Physiol 285:C899-C911.

Ueda H, Fujita R, Yoshida A, Matsunaga H, Ueda M (2007) Identification of prothymosin-alphal, the necrosis-apoptosis switch molecule in cortical neuronal cultures. J Cell Biol 176:853-862.

Waegell W, Babineau M, Hart M, Dixon K, McRae B, Wallace C, Leach M, Ratnofsky S, Belanger A, Hirst G, Rossini A, Appel M, Mordes J, Greiner D, Banerjee S (2002) A420983, a novel, small molecule inhibitor of LCK prevents allograft rejection. Transplant Proc 34:1411-1417.

Watanabe R, Ishiura N, Nakashima H, Kuwano Y, Okochi H, Tamaki K, Sato S, Tedder TF, Fujimoto M (2010) Regulatory B cells (B10 cells) have a suppressive role in murine lupus: CD19 and B10 cell deficiency exacerbates systemic autoimmunity. J Immunol 184:4801-4809.

Wetzel M, Li L, Harms KM, Roitbak T, Ventura PB, Rosenberg GA, Khokha R, Cunningham LA (2008) Tissue inhibitor of metalloproteinases- $3 \mathrm{fa}-$ cilitates Fas-mediated neuronal cell death following mild ischemia. Cell Death Differ 15:143-151.

Wu HY, Hsu FC, Gleichman AJ, Baconguis I, Coulter DA, Lynch DR (2007) Fyn-mediated phosphorylation of NR2B Tyr-1336 controls calpainmediated NR2B cleavage in neurons and heterologous systems. J Biol Chem 282:20075-20087.

Yim YI, Sun T, Wu LG, Raimondi A, De Camilli P, Eisenberg E, Greene LE (2010) Endocytosis and clathrin-uncoating defects at synapses of auxilin knockout mice. Proc Natl Acad Sci USA 107:4412-4417.

Zemke D, Smith JL, Reeves MJ, Majid A (2004) Ischemia and ischemic tolerance in the brain: an overview. Neurotoxicology 25:895-904. 